\title{
Health information regarding diabetes mellitus reduces misconceptions and underestimation of consequences in the general population
}

\author{
Thomas E Dorner ${ }^{1, *}$, Christian Lackinger ${ }^{2}$, Karin Schindler ${ }^{3}$, K Viktoria Stein $^{1}$, \\ Anita Rieder ${ }^{1}$ and Bernhard Ludvik ${ }^{3}$ \\ 'Institute of Social Medicine, Centre for Public Health, Medical University of Vienna, Rooseveltplatz 3, \\ 1090 Vienna, Austria: ${ }^{2}$ Sportunion, Vienna, Austria: ${ }^{3}$ Department of Medicine III, Division of Endocrinology \\ and Metabolism, Medical University of Vienna, Vienna, Austria
}

Submitted 19 March 2012: Final revision received 13 June 2012: Accepted 17 July 2012: First published online 29 August 2012

\begin{abstract}
Objective: To evaluate self-assessed knowledge about diabetes mellitus, to assess determinants of health knowledge and to evaluate consequences of health knowledge on appraisal about consequences of the disease.

Design: Population-based computer-assisted web interview survey, supplemented with a paper-and-pencil survey via post.

Setting: Representative sample of the general Austrian population aged 15 years and older.

Subjects: Men ( $n$ 1935) and women ( $n$ 2065) with and without diabetes mellitus. Results: Some $20 \cdot 5 \%$ of men and $17 \cdot 7 \%$ of women with diabetes, and $46 \cdot 2 \%$ of men and $36.7 \%$ of women without diabetes, rated their knowledge about diabetes mellitus to be 'very bad' or 'rather bad'. Individuals with diabetes and individuals with a family member with diabetes rated their information level more often as 'very good' or 'rather good', with adjusted OR (95\% CI) of 1.7 $(1 \cdot 1,2 \cdot 8)$ and $2 \cdot 1(1 \cdot 6,2 \cdot 7)$, respectively, in men and $2 \cdot 7(1 \cdot 5,4 \cdot 8)$ and $2 \cdot 7$ $(2 \cdot 1,3 \cdot 5)$, respectively, in women. Additional significant influencing factors on diabetes knowledge were age and educational level in both sexes, and city size in men. Independent of personal diabetes status, diabetes knowledge was associated with a lower perception of restrictions on daily life of diabetes patients and with a lower probability of underestimating health consequences of diabetes. Conclusions: Health knowledge is associated with fewer misconceptions and less underestimation of health consequences in individuals both with and without diabetes mellitus. Thus health information about diabetes is important on the individual level towards disease management as well as on the public health level towards disease prevention.
\end{abstract}

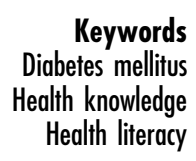

Adequate patient information has been defined as a high priority health policy issue. Health education has a high impact on understanding the causes and consequences of illness, protecting health, preventing complications and taking appropriate action towards managing chronic diseases $^{(1)}$. Health literacy, which is defined by the WHO as the cognitive and social skills which determine the motivation and ability of individuals to gain access to, understand und use information in ways which promote and maintain good health'(2), is a prerequisite for the empowerment of individuals to manage a disease, to prevent a disease or to promote health, independently of diseases. Therefore, health literacy is not only a personal resource, but also an important determinant of the health of a community ${ }^{(3)}$. In fact, both clinical and public health approaches to health literacy have been tested with different implications ${ }^{(4)}$. Low health literacy is associated with adverse health outcomes, independently of other risk factors ${ }^{(5)}$. It has been argued that health literacy can be regarded as a measurable outcome to health education and is best accessed when the content and context are well defined (e.g. for a person with diabetes mellitus who is or is not receiving patient education) $)^{(5)}$. In addition, greater health-related knowledge supports greater autonomy and personal empowerment in health-related decision making ${ }^{(5)}$.

Regarding diabetes mellitus, knowledge and health literacy are important to allow a healthy lifestyle with a sufficient amount of physical activity and healthy nutrition to prevent onset of the disease. For individuals 
who already suffer from diabetes mellitus, health literacy is a prerequisite to manage the disease with its challenges in lifestyle changes, adherence to the established therapy and navigation through the health-care system. In fact, in patients with diabetes mellitus, diabetes knowledge and health literacy are highly associated with each other and lead to better outcomes in diabetes ${ }^{(6-10)}$.

Most research regarding health knowledge and health literacy associated with diabetes mellitus has focused on patients with diagnosed and treated diabetes only. Little is known about diabetes-related health knowledge in individuals without known diabetes. This population is however also important, because these individuals can be at high risk for diabetes or even suffer from undiagnosed diabetes. Regarding the high prevalence of diabetes in the general population, there is a good chance to be personally involved in the management of diabetes of relatives or friends.

It was the aim of the present analysis to evaluate the self-assessed knowledge about diabetes mellitus in persons with and without diabetes mellitus. Furthermore, we sought to assess determinants of diabetes-related health knowledge and to evaluate consequences of health knowledge on adequate appraisal of the illness and its consequences in a sample representative for the general Austrian population.

\section{Methods}

\section{Sample}

The database used for the analysis was a populationbased survey carried out by a research institute in August and September 2009. The survey was performed for half of the participants as computer-assisted web interviews and for the other half as a paper-and-pencil survey via post with a structured questionnaire. With this mix of methods an optimal representativeness in all age strata is guaranteed, since Internet-savvy individuals (mostly younger persons) can use the Internet and those who have doubts about the confidentiality of the Internet or are not familiar with it can use the paper-and-pencil version via post (mostly elderly persons). The research institute routinely cooperates with 30000 panellists online and 20000 panellists via traditional mail. Both pools are recruited via telephone or personal contact, where no specific screening criteria are used. Both pools cover the entire Austrian population according to regional and demographic parameters. Out of this pool 4350 online panellists and 5200 postal panellists were randomly selected to participate in this specific survey, stratified by region and age. The online panellists received an email containing a personalized questionnaire link to assure that each was able to participate once only, and were reminded up to three times. The postal panellists received a printed questionnaire and one postal reminder.
Response rate in the online sample was $46.0 \%$ and in the postal pool $38.4 \%$. The total sample reached a response rate of $42 \cdot 1 \%$. Persons aged 15 years and older were included in the survey. In order to account for the stratification of the sample, the data were weighted by age, sex, country of origin and city size.

\section{Analysed variables}

Regarding diabetes mellitus, participants were asked: 'Have you ever been diagnosed with diabetes mellitus?'. If this was answered 'yes', participants were asked to indicate whether they had been diagnosed with type 1 diabetes, type 2 diabetes, gestational diabetes or if they did not know the diabetes classification.

Knowledge about diabetes was assessed with the question: 'Independently of your own diabetes status, how well do you feel informed about diabetes mellitus?'. Participants were asked to answer 'very good', 'rather good', 'rather bad' or 'very bad'. Furthermore, participants were asked: 'Which source of information about diabetes mellitus do you prefer?'. The answer was given in eight categories and 'other', where multiple answers were possible. Participants were also asked: 'Diabetes can, if not treated, lead to other diseases. Which of the following diseases do you know can be caused by diabetes mellitus?'. Nine categories of answers were offered; again, multiple answers were possible. Finally, participants were asked to rate on a 4 -point Likert scale ( $1=$ 'very strong', $2=$ 'rather strong', $3=$ 'rather little', $4=$ 'very little') restrictions in activities of daily living due to diabetes mellitus with the wording: 'Think of what you know about living with diabetes mellitus and indicate how the following activities of daily living are influenced in subjects with diabetes mellitus'. Seven different activities of daily living were asked.

As explanatory co-variables in the multivariate regression models, apart from personal diabetes status and age in years, the diabetes status of family members was assessed with the question: 'Do any of your family members suffer from diabetes mellitus type 1 or type 2?'. Household net income was assessed in eleven categories, education in six categories, city size in four categories and familial status in the categories 'married or civil union' and 'single, divorced, separated, widowed'. BMI was computed as $\mathrm{kg} / \mathrm{m}^{2}$ from self-reported data of body weight and body height.

\section{Statistical analysis}

Statistical analysis was conducted using the SPSS Statistics $17 \cdot 0$ statistical software package. Bivariate analyses were undertaken by means of cross-tabulations, and group differences were assessed with the Pearson's $\chi^{2}$ test. For assessment of the influence on diabetes knowledge, a logistic regression analysis was applied. The level of knowledge was used as the dependent variable and was dichotomized as feeling 'very well' or 'rather well' 
informed $v$. 'very badly' or 'rather badly' informed. The variables 'being affected by diabetes mellitus', 'having a family member with diabetes', 'living with a partner' and 'educational level' (primary, secondary and tertiary education) were used as categorical variables, and household net income, city size, BMI and age were used simultaneously as metric variables in the model. The results of the logistic regression model are presented as odds ratios with $95 \%$ confidence intervals. Nagelkerke's $R^{2}$ is presented as a measure of model fit. For the ratings of restrictions in activities of daily living due to diabetes mellitus, mean values were computed and Student's $t$ test used to assess differences between those who felt badly informed $v$. well informed about diabetes mellitus. All results were stratified by sex.

\section{Results}

\section{Response rate}

The response rate to the survey was $42 \%$, so a total of 1935 men and 2065 women were eligible for analysis. There were no missing data in the used variables, except for BMI in $1.0 \%$, ratings of knowledge in $3 \cdot 1 \%$ and household net income in $19 \cdot 9 \%$.

\section{Diabetes prevalence}

One hundred and twenty-nine men and 165 women (6.7\% and $8.0 \%$, respectively) reported that they had been diagnosed with diabetes mellitus. Out of these diabetes patients, $14 \cdot 0 \%$ of men and $16 \cdot 2 \%$ of women had been diagnosed with type 1 diabetes ( $n 18$ and 27),
$60 \cdot 1 \%$ of men and $49 \cdot 6 \%$ of women had a diagnosis of type 2 diabetes ( $n 78$ and 82), and $27 \cdot 6 \%$ of women ( $n$ 46) had been diagnosed with gestational diabetes. Some $24.9 \%$ of male and $8.5 \%$ of female diabetes patients reported that they did not know what kind of diabetes mellitus they had been diagnosed with ( $n 32$ and 14).

\section{Self-rated level of diabetes knowledge}

As shown in Fig. 1, in the total population, women tended to rate their level of knowledge about diabetes mellitus better than men. Individuals with diabetes mellitus rated their level of knowledge better than those without diabetes, although still $20.5 \%$ of men and $17 \cdot 7 \%$ of women ( $n 26$ and 29) with diabetes rated their level of knowledge about diabetes mellitus to be 'rather bad' or 'very bad'.

\section{Factors influencing diabetes knowledge}

A logistic regression model revealed that positive personal diabetes status had a high influence on being well informed about diabetes. Having a family member with diabetes was associated with a twofold greater chance in men and an almost threefold greater chance in women to have good information status, compared with the population without diabetic relatives. Age was associated with an increasing chance of being well informed about diabetes in both sexes, and in men, city size also had an effect on diabetes knowledge. Men with secondary education rated their level of information on diabetes lower than men with primary education. Women with secondary education, however, rated their level of information higher than women with primary education.

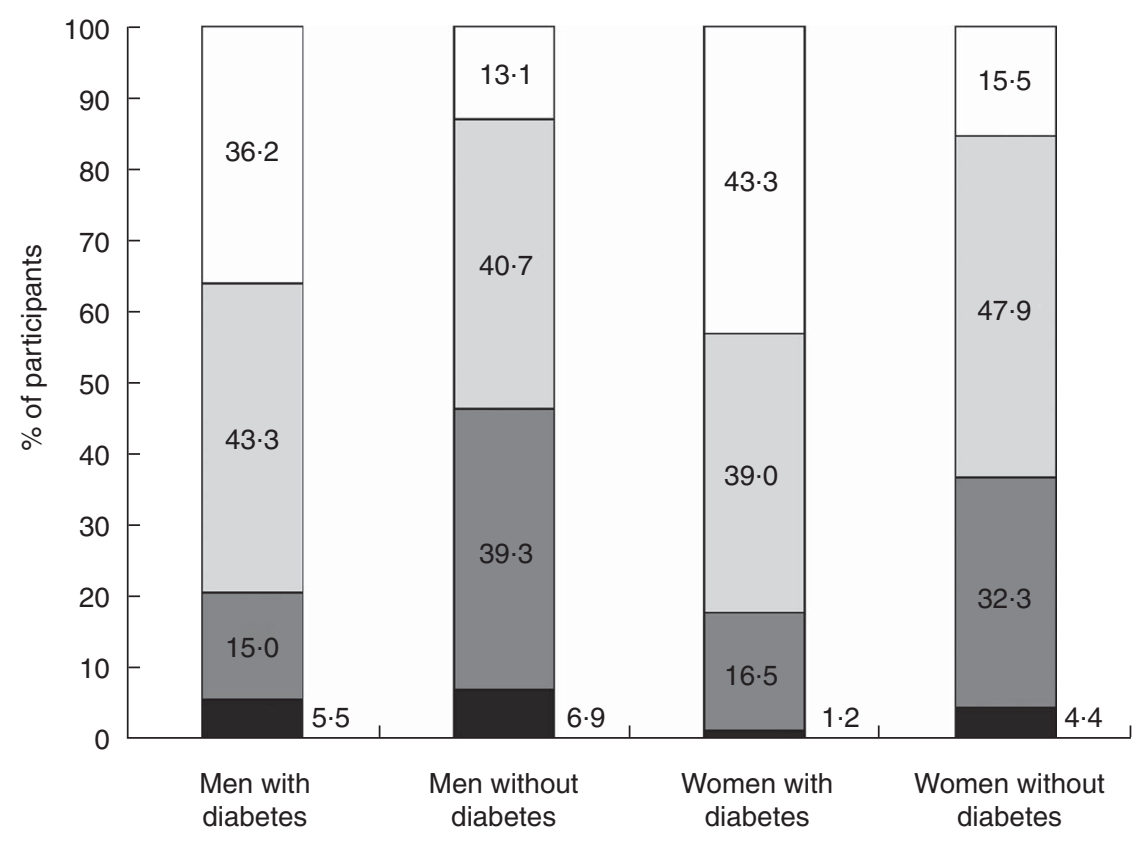

Fig. 1 Level of knowledge about diabetes mellitus ( $\square$, 'very good'; $\square$, 'rather good'; $\square$, 'rather bad'; $\square$, 'very bad') in men ( $n$ 1935) and women ( $n$ 2065) with and without diabetes mellitus; Austria, August/September 2009 
Table 1 Logistic regression results for subjectively feeling very well or rather well informed about diabetes mellitus; all variables are simultaneously included in the model. Men $(n 1935)$ and women $(n 2065)$ with and without diabetes mellitus; Austria, August/September 2009

\begin{tabular}{|c|c|c|c|c|c|c|}
\hline & \multicolumn{3}{|c|}{ Men $(n$ 1557) } & \multicolumn{3}{|c|}{ Women $(n$ 1558) } \\
\hline & OR & $95 \% \mathrm{Cl}$ & $P$ & OR & $95 \% \mathrm{Cl}$ & $P$ \\
\hline Having diabetes (reference: not having diabetes) & $1 \cdot 71$ & $1 \cdot 05,2 \cdot 79$ & 0.032 & $2 \cdot 66$ & $1 \cdot 47,4 \cdot 81$ & 0.001 \\
\hline $\begin{array}{l}\text { Family member having diabetes } \\
\text { (reference: no family member with diabetes) }\end{array}$ & $2 \cdot 07$ & $1 \cdot 60,2 \cdot 68$ & $<0.001$ & $2 \cdot 72$ & $2 \cdot 09,3.53$ & $<0.001$ \\
\hline $\begin{array}{l}\text { Being married or living with a partner } \\
\text { (reference: single/divorced/separated/widowed) }\end{array}$ & 0.94 & $0 \cdot 72,1 \cdot 22$ & 0.657 & 0.89 & $0 \cdot 69,1 \cdot 14$ & 0.358 \\
\hline Secondary education (reference: primary education) & 0.58 & $0 \cdot 40,0 \cdot 86$ & 0.007 & $1 \cdot 40$ & $1 \cdot 01,1.95$ & 0.043 \\
\hline Tertiary education (reference: primary education) & 0.98 & $0.61,1.58$ & 0.939 & $1 \cdot 51$ & $1 \cdot 00,2 \cdot 29$ & 0.052 \\
\hline Household net income & 0.98 & $0.90,1.01$ & $0 \cdot 362$ & 0.98 & $0.90,1.06$ & 0.589 \\
\hline City size & $1 \cdot 13$ & $1 \cdot 05,1 \cdot 22$ & 0.002 & $1 \cdot 03$ & $0.95,1.12$ & 0.417 \\
\hline BMl $\left(\mathrm{kg} / \mathrm{m}^{2}\right)$ & 0.99 & $0.97,1.01$ & $0 \cdot 362$ & $1 \cdot 02$ & $1.00,1.04$ & $0 \cdot 101$ \\
\hline Age (years) & $1 \cdot 03$ & $1 \cdot 03,1 \cdot 04$ & $<0.001$ & $1 \cdot 03$ & $1 \cdot 02,1 \cdot 03$ & $<0.001$ \\
\hline$R^{2}$ & \multicolumn{3}{|c|}{0.129} & \multicolumn{3}{|c|}{$0 \cdot 136$} \\
\hline
\end{tabular}

Family status, household net income and BMI were not significant predictors of being well informed about diabetes in either sex (Table 1).

\section{Knowledge and bealth consequences}

The proportion of the total population who linked diabetes mellitus to impaired wound healing and eye disease was $65.5 \%$ and $62.7 \%$, respectively, in men and $78.6 \%$ and $76.9 \%$, respectively, in women. However, the proportion who associated diabetes with vessel diseases, stroke or atherosclerosis was only $39 \cdot 6 \%, 39 \cdot 3 \%$ and $14 \cdot 1 \%$, respectively, in men and $49 \cdot 5 \%, 40 \cdot 3 \%$ and $15 \cdot 3 \%$, respectively, in women. In individuals who subjectively felt better informed about diabetes mellitus, the proportion who correctly knew that diabetes can lead to various diseases was significantly higher compared with those who rated their level of knowledge as low, regardless of personal diabetes status. Women considered all diseases to be a possible consequence of diabetes mellitus more often than men (Table 2).

\section{Restrictions in daily life}

Regarding restrictions in lifestyle due to diabetes, men and women rated diet to be most influenced by diabetes on a scale between 1 ('very strong') and 4 ('very little') with a mean of 1.82 for both sexes, and restrictions in possibilities to participate in sports least. Men rated restrictions in physical capacity and restrictions in possibilities to participate in sports due to diabetes higher than women (2.57 v. 2.46, $P<0.001$ and 3.00 v. 2.93, $P=0.006$, respectively). Interestingly, patients with diabetes mellitus rated restrictions in diet, in physical capacity, in mental resilience and in possibilities to participate in sports lower than did individuals without diabetes mellitus $(2.05 v$. $1 \cdot 08, P<0 \cdot 001 ; 2 \cdot 66$ v. $2 \cdot 51, P=0 \cdot 005 ; 2 \cdot 86$ v. $2 \cdot 68$, $P<0.001$; and $3 \cdot 12$ v. $2 \cdot 95, P=0 \cdot 001$, respectively). Individuals who felt informed about diabetes mellitus tended to indicate that diabetes was associated with restrictions in daily activities and quality of life to a lower extent than did those who indicated not to be well informed about diabetes mellitus (Table 3).

\section{Source of information}

Men indicated to consult a doctor and the Internet for information about diabetes more often than women, and women indicated more often than men to consult a pharmacy, newspapers, magazines, folders and brochures, support groups or other sources for diabetes information. Male and female patients with diabetes consulted a doctor for information on diabetes respectively 1.36 times and 1.41 times more often compared with individuals without diabetes, and female diabetes patients got information from support groups more than three times more often than non-diabetic females. Male participants without diabetes got information almost twice as often from the Internet and almost five times more often from other sources compared with diabetic males, and female participants without diabetes got information more than three times as often from the radio than did female diabetes patients (Table 4).

\section{Discussion}

Our results show that a large proportion of the general adult population rates its level of knowledge about diabetes mellitus to be low, and even among diabetes patients more than a fifth feel badly informed about diabetes mellitus. A lack of knowledge about diabetes is associated with greater misconceptions about possible restrictions due to the disease and with a greater amount of underestimation of diabetes consequences, both in those with and without diabetes.

\section{Predictors of information level}

Significant influences on knowledge about diabetes mellitus were exerted by personal diabetes status, diabetes status of family members, educational level, city 
Table 2 Percentage of participants who indicated that diabetes mellitus can lead to a certain disease by subjective level of knowledge about diabetes mellitus: men ( $n$ 1935) and women ( $n$ 2065) with and without diabetes mellitus; Austria, August/September 2009

\begin{tabular}{|c|c|c|c|c|c|c|c|c|c|c|c|c|}
\hline & \multicolumn{3}{|c|}{$\begin{array}{l}\text { Men with diabetes } \\
\qquad(n 127)\end{array}$} & \multicolumn{3}{|c|}{$\begin{array}{l}\text { Women with diabetes } \\
\qquad(n \text { 165) }\end{array}$} & \multicolumn{3}{|c|}{$\begin{array}{l}\text { Men without diabetes } \\
(n \text { 1755) }\end{array}$} & \multicolumn{3}{|c|}{$\begin{array}{l}\text { Women without diabetes } \\
\qquad(n \text { 1830) }\end{array}$} \\
\hline & $\begin{array}{l}\text { 'Very bad' or } \\
\text { 'rather bad' }\end{array}$ & $\begin{array}{l}\text { 'Very good' or } \\
\text { 'rather good' }\end{array}$ & $P$ & $\begin{array}{l}\text { 'Very bad' or } \\
\text { 'rather bad' }\end{array}$ & $\begin{array}{l}\text { 'Very good' or } \\
\text { 'rather good' }\end{array}$ & $P$ & $\begin{array}{l}\text { 'Very bad' or } \\
\text { 'rather bad' }\end{array}$ & $\begin{array}{l}\text { 'Very good' or } \\
\text { 'rather good' }\end{array}$ & $P$ & $\begin{array}{l}\text { 'Very bad' or } \\
\text { 'rather bad' }\end{array}$ & $\begin{array}{l}\text { 'Very good' or } \\
\text { 'rather good' }\end{array}$ & $P$ \\
\hline Bad healing wounds & $46 \cdot 2$ & $84 \cdot 2$ & $<0.001$ & $78 \cdot 7$ & $92 \cdot 6$ & 0.009 & $50 \cdot 6$ & $78 \cdot 4$ & $<0.001$ & $62 \cdot 8$ & $87 \cdot 7$ & $<0.001$ \\
\hline Eye diseases & $68 \cdot 0$ & $85 \cdot 3$ & 0.044 & $60 \cdot 0$ & $94 \cdot 8$ & $<0.001$ & $47 \cdot 9$ & $74 \cdot 4$ & $<0.001$ & $63 \cdot 3$ & $84 \cdot 8$ & $<0.001$ \\
\hline Vessel diseases & $19 \cdot 2$ & $67 \cdot 3$ & $<0.001$ & $41 \cdot 4$ & $83 \cdot 7$ & $<0.001$ & $25 \cdot 6$ & $50 \cdot 7$ & $<0.001$ & $31 \cdot 3$ & $57 \cdot 8$ & $<0.001$ \\
\hline Atherosclerosis & $28 \cdot 0$ & $22 \cdot 8$ & 0.583 & $6 \cdot 9$ & $29 \cdot 9$ & $0 \cdot 010$ & $5 \cdot 6$ & $20 \cdot 6$ & $<0.001$ & $5 \cdot 8$ & $19 \cdot 8$ & $<0.001$ \\
\hline Stroke & $34 \cdot 6$ & $62 \cdot 4$ & 0.011 & $30 \cdot 0$ & $63 \cdot 0$ & 0.001 & $28 \cdot 9$ & $46 \cdot 6$ & $<0.001$ & $27 \cdot 9$ & $46 \cdot 1$ & $<0.001$ \\
\hline
\end{tabular}

Table 3 Rating of restrictions due to diabetes mellitus in participants by subjective level of knowledge about diabetes mellitus: men ( $n$ 1935) and women ( $n$ 2065) with and without diabetes mellitus; Austria, August/September 2009

\begin{tabular}{|c|c|c|c|c|c|c|c|c|c|c|c|c|}
\hline & \multicolumn{3}{|c|}{$\begin{array}{l}\text { Men with diabetes } \\
(n \text { 127) }\end{array}$} & \multicolumn{3}{|c|}{$\begin{array}{l}\text { Women with diabetes } \\
\qquad(n \text { 165) }\end{array}$} & \multicolumn{3}{|c|}{$\begin{array}{l}\text { Men without diabetes } \\
(n \text { 1755) }\end{array}$} & \multicolumn{3}{|c|}{$\begin{array}{l}\text { Women without diabetes } \\
(n \text { 1830) }\end{array}$} \\
\hline & $\begin{array}{l}\text { 'Very bad' } \\
\text { or 'rather } \\
\text { bad' }\end{array}$ & $\begin{array}{l}\text { 'Very good' } \\
\text { or 'rather } \\
\text { good' }\end{array}$ & $P$ & $\begin{array}{l}\text { 'Very bad' } \\
\text { or 'rather } \\
\text { bad' }\end{array}$ & $\begin{array}{l}\text { 'Very good' } \\
\text { or 'rather } \\
\text { good' }\end{array}$ & $P$ & $\begin{array}{l}\text { 'Very bad' } \\
\text { or 'rather } \\
\text { bad' }\end{array}$ & $\begin{array}{l}\text { 'Very good' } \\
\text { or 'rather } \\
\text { good' }\end{array}$ & $P$ & $\begin{array}{l}\text { 'Very bad' } \\
\text { or 'rather } \\
\text { bad' }\end{array}$ & $\begin{array}{l}\text { 'Very good' } \\
\text { or 'rather } \\
\text { good' }\end{array}$ & $P$ \\
\hline Restrictions in diet & $1 \cdot 81$ & $2 \cdot 03$ & $0 \cdot 181$ & $1 \cdot 77$ & $2 \cdot 19$ & 0.019 & $1 \cdot 75$ & $1 \cdot 78$ & 0.430 & 1.67 & $1 \cdot 79$ & $<0.001$ \\
\hline Restrictions in physical capacity & $2 \cdot 21$ & $2 \cdot 78$ & 0.003 & $2 \cdot 34$ & $2 \cdot 69$ & 0.064 & $2 \cdot 37$ & $2 \cdot 44$ & 0.070 & $2 \cdot 47$ & $2 \cdot 58$ & 0.009 \\
\hline Restrictions in mental resilience & $2 \cdot 24$ & 2.99 & $<0.001$ & $2 \cdot 65$ & $2 \cdot 91$ & $0 \cdot 198$ & $2 \cdot 61$ & $2 \cdot 65$ & 0.343 & $2 \cdot 64$ & $2 \cdot 65$ & 0.906 \\
\hline Restrictions in mobility & $2 \cdot 56$ & 3.03 & 0.033 & $2 \cdot 60$ & $2 \cdot 99$ & 0.046 & $2 \cdot 80$ & $2 \cdot 84$ & 0.355 & $2 \cdot 80$ & $2 \cdot 88$ & 0.059 \\
\hline $\begin{array}{l}\text { Restrictions in possibilities to } \\
\text { participate in sports }\end{array}$ & $2 \cdot 80$ & $3 \cdot 12$ & $0 \cdot 113$ & $2 \cdot 78$ & $3 \cdot 23$ & 0.016 & $2 \cdot 81$ & 2.95 & $<0.001$ & $2 \cdot 90$ & $2 \cdot 98$ & 0.017 \\
\hline Restrictions in coping with distress & $2 \cdot 40$ & $2 \cdot 88$ & 0.020 & $2 \cdot 39$ & $2 \cdot 78$ & 0.039 & $2 \cdot 60$ & $2 \cdot 67$ & 0.031 & $2 \cdot 65$ & $2 \cdot 68$ & 0.453 \\
\hline
\end{tabular}

Mean value on a 4-point Likert scale between $1=$ 'very strong' and $4=$ 'very little'. 
Table 4 Percentage of participants who indicated a specific source of information about diabetes mellitus by sex and personal diabetes status: men ( $n$ 1935) and women ( $n$ 2065) with and without diabetes mellitus; Austria, August/September 2009

\begin{tabular}{|c|c|c|c|c|c|c|}
\hline & \multicolumn{3}{|c|}{ Men } & \multicolumn{3}{|c|}{ Women } \\
\hline & $\begin{array}{l}\text { Diabetes } \\
\text { mellitus } \\
(n 129)\end{array}$ & $\begin{array}{c}\text { No diabetes } \\
\text { mellitus } \\
(n \text { 1906)† }\end{array}$ & $\begin{array}{c}\text { Total } \\
(n 1935)\end{array}$ & $\begin{array}{l}\text { Diabetes } \\
\text { mellitus } \\
(n 165)\end{array}$ & $\begin{array}{c}\text { No diabetes } \\
\text { mellitus } \\
(n \text { 1900) } \dagger\end{array}$ & $\begin{array}{c}\text { Total } \\
(n \text { 2065) }\end{array}$ \\
\hline Consultation of a doctor & $90 \cdot 7$ & $66 \cdot 6^{\star \star \star}$ & $68 \cdot 2$ & $85 \cdot 5$ & $60 \cdot 8^{* \star *}$ & $62 \cdot 8^{\star \star \star}$ \\
\hline Consultation of a pharmacy & $4 \cdot 7$ & $7 \cdot 9$ & $7 \cdot 6$ & $10 \cdot 3$ & $9 \cdot 7$ & $9 \cdot 8^{*}$ \\
\hline Television & $13 \cdot 2$ & $16 \cdot 3$ & $16 \cdot 1$ & $12 \cdot 7$ & $16 \cdot 4$ & $16 \cdot 1$ \\
\hline Radio & $2 \cdot 3$ & $5 \cdot 3$ & $5 \cdot 1$ & $1 \cdot 8$ & $5 \cdot 7^{*}$ & $5 \cdot 4$ \\
\hline Newspaper, magazines & $27 \cdot 1$ & $23 \cdot 5$ & $23 \cdot 7$ & $26 \cdot 7$ & $28 \cdot 3$ & $28 \cdot 1^{\star \star}$ \\
\hline Internet & $20 \cdot 2$ & $38 \cdot 0^{\star \star \star}$ & $36 \cdot 9$ & $33 \cdot 1$ & $33 \cdot 2$ & $33 \cdot 2^{*}$ \\
\hline Folders, brochures & $17 \cdot 8$ & $21 \cdot 7$ & $21 \cdot 4$ & $30 \cdot 9$ & $25 \cdot 4$ & $25 \cdot 9^{* *}$ \\
\hline Support groups & $3 \cdot 9$ & 1.9 & $2 \cdot 0$ & $8 \cdot 5$ & $2 \cdot 7^{\star \star \star}$ & $3 \cdot 2^{*}$ \\
\hline Other & $1 \cdot 6$ & $7 \cdot 6^{\star}$ & $7 \cdot 2$ & $12 \cdot 1$ & $9 \cdot 5$ & $9 \cdot 7^{* *}$ \\
\hline
\end{tabular}

${ }^{\star} P<0.05,{ }^{* *} P<0.01,{ }^{* * *} P<0.001$.

t $P$ value between participants with diabetes $v$. without diabetes.

$\ddagger P$ value between total men and women.

size and age. In another Austrian survey, older age, higher educational level and bigger city size were also found to be associated with better knowledge about the cardiovascular risk factor low HDL-cholesterol compared with their opposites ${ }^{(11)}$. A recent study of 200 diabetes patients showed that a higher degree of health knowledge was associated with younger age, a low number of children, educational level and diabetes duration ${ }^{(12)}$. Health literacy has also been found to be dependent on educational level, sex and race in another study ${ }^{(13)}$. The fact that educational level has an influence on health literacy is especially important regarding the prevention of diabetes, since a low socio-economic status is associated with a higher risk of diabetes ${ }^{(14,15)}$. Thus, even in individuals without known diabetes, those with a lower socio-economic status should be considered a special target group for education about diabetes-related issues. As the association of poor health literacy with worse outcomes in diabetes mellitus has been found to be independent of socio-economic status ${ }^{(7)}$, information on diabetes should be given disregarding educational status.

Interestingly, in our survey men with secondary education felt to be less informed about diabetes mellitus, while women with secondary education felt better informed than women with primary education. However, men and women with tertiary education did not feel significantly better informed than those with primary education. This could be explained by the fact that higher educated persons might regard their level of experience more critically and might thus consider lack of information more often as a deficit compared with persons with lower education. Income had no influence on the level of feeling informed about diabetes mellitus in our study after adjusting for other predictors.

\section{Diabetes status of family members}

For men and women, the diabetes status of a family member was more strongly associated with diabetes knowledge than personal diabetes status, especially in men. An explanation for this finding could be that individuals with diabetic relatives take responsibility for their care and seek information. In another study, it has been shown that family members facilitate health literacy in diabetes patients ${ }^{(16)}$.

\section{Restrictions in daily life}

We found that a higher level of diabetes knowledge was associated with lower ratings of presumed limitations in activities of daily living among men and women, regardless of diabetes status. Thus, health literacy and health knowledge have a high potential to take away some of the fear which might be associated with the diagnosis of diabetes mellitus. This could in turn lead to the perception that diabetes is not necessarily associated with a lower quality of life or potential restrictions. In a correlation study it was shown that learned resourcefulness, which can be understood as a part of health literacy, was associated with better quality of life in patients with diabetes mellitus ${ }^{(17)}$.

\section{Source of information}

Despite emerging new important sources of health information like the Internet, doctors were still the major source of information on diabetes, regardless of personal diabetes status, among our study participants. Thus doctors should be aware of their role not only in diabetes management, but also in diabetes prevention. Health check-ups in healthy individuals should also be regarded as a window of opportunity to consult towards a healthy lifestyle and measures to prevent diabetes mellitus. However, the Internet is also regarded as an important tool for information about diabetes, especially among men without diabetes. In that regard, a German study has demonstrated the feasibility of a computer-based lifestyle counselling in diabetes patients ${ }^{(18)}$. 


\section{Healtb literacy in diabetes patients}

Other studies which research health literacy in diabetes mellitus usually focus on persons who are already affected by diabetes and therefore are not concerned with the prevention of diabetes. These studies show that, in patients with diabetes mellitus, health literacy leads to greater diabetes knowledge, is associated with self-efficacy and self-care behaviours and leads to a better glycaemic control $^{(6-10)}$. Health literacy additionally is associated with improved adherence to diabetes medication ${ }^{(19)}$. Another model that links poor health literacy to worse glycaemic control assumes that health literacy is associated with patient satisfaction and patient-provider communication, and in consequence leads to poor glycaemic control ${ }^{(16)}$. In contrast, a high level of diabetes knowledge is associated with increased medication adherence and better glycaemic control $^{(20)}$.

\section{Applications for public bealth}

Health literacy and health knowledge have been argued to have implications not only on individual health outcomes, but also on the health of a community ${ }^{(3-5)}$. In fact, community-based health education to promote a healthy lifestyle has substantial effects on primary and secondary prevention $^{(21,22)}$. Our study reinforces the necessity for health information targeted towards the healthy population, not only for the prevention of diabetes mellitus but also for the prevention of misconceptions associated with diabetes mellitus. A well-informed public might also take away some of stigmas that are still connected with diabetes mellitus in the perception of the patients concerned ${ }^{(23)}$.

\section{Strengtbs and limitations}

One of the strengths of our study is that self-perceived health knowledge regarding diabetes mellitus was simultaneously assessed in persons with and without diabetes. This approach is not common in studies assessing diabetesrelated health literacy. Another advantage is the large sample size of our study and the representativeness for the general Austrian population, according to geographic and sociodemographic parameters. Due to the selection of participants contacted, generalization of the results to the entire population should be made with care.

A potential limitation may be that we did not use proven and tested tools to assess health literacy, which exist specifically for diabetes patients as well as in generic forms for the general population. Moreover, the selfreported level of feeling informed about diabetes mellitus was not objectified by assessment of actual diabetes knowledge. This might lead to an underestimation of actual lack of diabetes knowledge. However, asking merely the question how informed one feels about diabetes mellitus, which we used as our primary outcome variable, reflects the subjective perception of level of knowledge. The self-perceived level of being informed about diabetes mellitus is, from the patient's point of view, possibly a more valid indicator of health literacy than objective knowledge.

Another possible limitation originates from the selfreported nature of the data and the response rate of just $42 \%$. Both aspects could affect the assessed diabetes prevalence. So, it could be that undiagnosed diabetes patients were a part of the non-diabetes group, which would result in a false-too-small diabetes prevalence. On the other hand, it could also be that diabetes patients were more likely to respond to the survey than nondiabetic patients, which would result in a false-too-high prevalence. Prevalence rates of diabetes mellitus in the present survey were $6.7 \%$ and $8.0 \%$ of affected men and women, quite similar to the results of the Austrian Health Interview Survey $2006 / 07$ where $5 \cdot 4 \%$ of men and $6.4 \%$ of women reported to have been diagnosed with diabetes mellitus ${ }^{(24)}$. The main outcomes of the current paper, i.e. health knowledge in individuals with and without diabetes, should however not be affected by these limitations.

Further research based on our study could include prospective studies regarding an increase of diabetes knowledge and health literacy in the general population on the risk of developing diabetes mellitus.

\section{Conclusions}

Our study shows that large proportions of patients and non-diabetic individuals do not feel satisfyingly informed about diabetes mellitus. Health knowledge needs to be improved in order to facilitate a sufficient health literacy, which in turn would lead to improved metabolic control of diabetes patients and improved prevention in non-diabetic individuals. Importantly, doctors still are considered the most important resource of health information and should therefore be aware of their responsibility in consulting individuals about diabetes mellitus related issues, especially with a focus on prevention. A high level of knowledge also leads to reduced misconceptions of potential restrictions in areas of life associated with diabetes mellitus. Thus, improving knowledge and health literacy regarding diabetes mellitus must also be considered an important task for public health.

\section{Acknowledgements}

Source of funding: Data collection was financially supported by a grant from the company Sanofi Aventis. The data were provided for analysis by the Austrian Diabetes Initiative. Conflicts of interest: The authors declare that they have no conflicts of interest. Authors' contributions: T.E.D. developed the idea of the manuscript and was responsible for the analysis of the data. T.E.D., K.S. and K.V.S. drafted and wrote the manuscript. C.L., A.R. and 
B.L. contributed to the interpretation of the data and in revising the manuscript critically. All authors read and approved the final manuscript.

\section{References}

1. Coulter A, Parsons S \& Askham J; World Health Organization, on behalf of the European Observatory on Health Systems and Policies (2008) Where are the Patients in Decision-making about Their Own Care? Geneva: WHO.

2. Nutbeam D (1998) Health promotion glossary. Health Promot Int 13, 349-364.

3. Kickbusch IS (2001) Health literacy: addressing the health and education divide. Health Promot Int 16, 289-297.

4. Pleasant A \& Kuruvilla S (2008) A tale of two health literacies: public health and clinical approaches to health literacy. Health Promot Int 23, 152-159.

5. Nutbeam D (2009) Defining and measuring health literacy: what can we learn from literacy studies? Int J Public Health 54, 303-305.

6. Cavanaugh KL (2011) Health literacy in diabetes care: explanation, evidence and equipment. Diabetes Manag (Lond) 1, 191-199.

7. Marden S, Thomas PW, Sheppard ZA et al. (2012) Poor numeracy skills are associated with glycaemic control in type 1 diabetes. Diabet Med 29, 662-669.

8. McCleary-Jones V (2011) Health literacy and its association with diabetes knowledge, self-efficacy and disease selfmanagement among African Americans with diabetes mellitus. ABNF J 22, 25-32.

9. Osborn CY, Cavanaugh K, Wallston KA et al. (2010) Selfefficacy links health literacy and numeracy to glycemic control. J Health Commun 15, Suppl. 2, 146-158.

10. Yamashita T \& Kart CS (2011) Is diabetes-specific health literacy associated with diabetes-related outcomes in older adults? J Diabetes 3, 138-146.

11. Dorner T, Fodor JG, Lawrence $\mathrm{K}$ et al. (2007) HDLknowledge in the lay public: results of a representative population survey. Atherosclerosis 195, 195-198.

12. Guler N \& Oguz S (2011) The spoken knowledge of low literacy in patients with diabetes. Diabetes Res Clin Pract 92, 238-243.
13. Jeppesen KM, Coyle JD \& Miser WF (2009) Screening questions to predict limited health literacy: a crosssectional study of patients with diabetes mellitus. Ann Fam Med 7, 24-31.

14. Dorner T, Rathmanner T \& Lechleitner M (2006) Public health aspects of diabetes mellitus - epidemiology, prevention strategies, policy implications: the first Austrian diabetes report. Wien Klin Wochenschr 118, 513-519.

15. Stein KV, Rieder A \& Dorner TE (2011) East-west gradient in cardio-vascular mortality in Austria: how much can we explain by following the pattern of risk factors? Int J Health Geogr 10, 59.

16. Mayberry LS, Kripalani S, Rothman RL et al. (2011) Bridging the digital divide in diabetes: family support and implications for health literacy. Diabetes Technol Ther 13, 1005-1012.

17. Huang CY, Perng SJ, Chen HF et al. (2008) The impact of learned resourcefulness on quality of life in type II diabetic patients: a cross-sectional correlational study. J Nurs Res 16, 264-274.

18. Becker A, Herzberg D, Marsden N et al. (2011) A new computer-based counselling system for the promotion of physical activity in patients with chronic diseases - results from a pilot study. Patient Educ Couns 83, 195-202.

19. Osborn CY, Cavanaugh K, Wallston KA et al. (2011) Health literacy explains racial disparities in diabetes medication adherence. J Health Commun 16, Suppl. 3, 268-278.

20. Al-Qazaz HKh, Sulaiman SA, Hassali MA et al. (2011) Diabetes knowledge, medication adherence and glycemic control among patients with type 2 diabetes. Int J Clin Pharm 33, 1028-1035.

21. Aarva P, de Haes W \& Visser A (1997) Health communication research. Patient Educ Couns 30, 1-5.

22. Kok G, van den Borne B \& Dolan Mullen P (1997) Effectiveness of health education and health promotion: meta-analyses of effect studies and determinants of effectiveness. Patient Educ Couns 30, 17-25.

23. Adams OP \& Carter AO (2011) Knowledge, attitudes, practices, and barriers reported by patients receiving diabetes and hypertension primary health care in Barbados: a focus group study. BMC Fam Pract 12, 135.

24. Statistik Austria (2007) Österreichische Gesundheitsbefragung 2006/07, Hauptergebnisse und methodische Dokumentation. Vienna: Bundesministerium für Gesundheit, Familie und Jugend. 